\title{
Simple hypertrophic tonsils have more active innate immune and inflammatory responses than hypertrophic tonsils with recurrent inflammation in children
}

\author{
Qun Huang ${ }^{1+}, \mathrm{Hu} \mathrm{Hua}^{2+}$, Wei $\mathrm{Li}^{1}, \mathrm{Xi} \mathrm{Chen}^{3}$ and Lei Cheng ${ }^{3 *}$ (D)
}

\begin{abstract}
Background: Tonsil hypertrophy has negative impact on children's health, but its pathogenesis remains obscure despite the fact that numerous bacteriological studies have been carried out. Understanding the innate immune and inflammatory states of hypertrophic tonsils with different clinical manifestations is of great significance for defining the pathogenesis of tonsil hypertrophy and establishing treatment strategies. The present study was undertaken to examine the characteristics of innate immunity and inflammation in children with hypertrophic palatine tonsils and different clinical manifestations.
\end{abstract}

Methods: Tonsil tissues were surgically removed from the patients and classified based on the patients' clinical manifestations. The patients were divided into three groups: 1) Control group; 2) Tonsil Hypertrophy (TH) group; and 3) Tonsil Hypertrophy combined with Recurrent Infection (TH + RI) group. The immune and inflammatory statuses of these tissues were characterized using qRT-PCR and ELISA methods.

Results: Viral protein 1 (VP1) was highly expressed in TH group, but not in TH + RI group. In TH group, elevated expression was observed in the innate immune mediators, including retinoic acid-inducible gene I (RIG-I), interferon alpha (IFN-a), mitochondrial antiviral-signaling protein (MAVS), NLR family pyrin domain containing 3 (NLRP3), tolllike receptor (TLR) 4 and TLR7. Consistent with the innate immune profile, the expression of inflammatory markers (IL-1 $\beta, N F-K B$ and IL-7) was also significantly elevated in TH group. Meanwhile, the COX-2/PGE2/EP4 signaling pathway was found to be involved in the inflammatory response and the formation of fibroblasts.

Conclusions: Innate immune and inflammatory responses are more active in simple hypertrophic tonsils, rather than hypertrophic tonsils with recurrent inflammation. A local relative immune deficiency in the hypertrophic tonsils may be a causative factor for recurrent tonsillitis in TH + RI. These differences, together with the patient's clinical manifestations, suggest that tonsillar hypertrophy might be regulated by diverse immune and/or inflammatory mechanism through which novel therapeutic strategies might be created.

Keywords: Palatine tonsil, Hypertrophy, Tonsillitis, Innate immunity, Inflammation, Infection

\footnotetext{
* Correspondence: chenglei@jsph.org.cn

${ }^{\dagger}$ Qun Huang and Hu Hua contributed equally to this work.

${ }^{3}$ Department of Otorhinolaryngology, The First Affiliated Hospital, Nanjing Medical University, 300 Guangzhou Road, Nanjing 210029, Jiangsu, China Full list of author information is available at the end of the article
} 


\section{Background}

The tonsil is an independent organ constructed by mucosal-associated lymphoid tissue (MALT). As the first stronghold against foreign pathogens, the tonsil can selectively regulate immune response in the internal environment $[1,2]$. Simple tonsil hypertrophy refers to the enlargement of the tonsil uncomplicated with inflammation. Lymphoid tissue degenerates in adulthood. Therefore, tonsil hypertrophy is much more prevalent, characteristic [3-5], and causative to obstructive sleepdisordered breathing (SDB) in children [6]. Also in children, the tonsil can kindle infections that may give rise to acute or chronic tonsillitis [7]. Symptoms of tonsillitis include sore throat, fever, enlargement of the tonsil, difficult swallowing, and swollen lymph nodes around the neck. Recurrent tonsillitis (RI) is diagnosed when tonsillitis relapses as sympomized by $\geq 7$ episodes of throat infection (well-documented, clinically important, adequately treated) in the preceding year, or $\geq 5$ episodes in each of the preceding 2 years, or $\geq 3$ episodes in each of the preceding 3 years [8].

Tonsillar disease is routinely treated with antibiotics or tonsillectomy [9]. Tonsillectomy is most recommended for children who meet the standards of the AAO-HNS tonsillectomy guidelines [10], but controversy still exists in the indications and the benefits/ harms after eliminating this immune organ [11]. Although numerous studies have been carried out to explore the bacteriology in the tonsil, the underlying pathogenic mechanism of tonsil hypertrophy has not been fully understood.

Tonsil hypertrophy exhibits varying clinical manifestations, either as simple hypertrophy or hypertrophy accompanied with recurrent inflammation. These different clinical manifestations suggest that tonsillar hypertrophy might be regulated by diverse immune and/or inflammatory mechanisms. But so far, there have been few reports analyzing these differences. This study, therefore, aimed to demonstrate the differences in innate immune and inflammatory responses in tonsils with various clinical manifestations, which will refresh our understanding of the pathology of tonsil hypertrophy and improve related clinical prevention and treatment.

\section{Methods}

\section{Human tissue samples}

This study was reviewed and approved by the institutional review board. Informed consent was obtained from the legal caregiver of each participant. Before surgery, the children who underwent tonsillectomy for either SDB or RI were identified. The diagnosis of SDB was established by a spectrum of breathing disorders during sleep, habitual and loud snoring, and upper airway obstruction [6]. RI was clinically diagnosed if the patient had a history of tonsillitis and sore throat ( $\geq 3$ infections per year in 3 years) that failed to respond to antibiotics. The degree of tonsil hypertrophy was scored from $1+$ to $4+$ according to the percentage of decreased pharyngeal lumen diameter [12-14]: 1+, 0-25\%; 2+, 26$50 \% ; 3+, 51-75 \%$ and $4+, 76-100 \%$. Tonsil hypertrophy was scored 3-4+ preoperatively [15].

Patients advised to undergo tonsillectomy (TE) in accordance with the AAO-HNS tonsillectomy guidelines [10], were recruited into the study. Consecutive patients were divided into three groups according to the clinical manifestations of their tonsils: 1) control group; 2) tonsil hypertrophy (TH) group; and 3) tonsil hypertrophy combined with recurrent infection $(\mathrm{TH}+\mathrm{RI}$ ) group. Included were those [1]: aged 2 to 13 years [2]; exhibiting significant symptoms of snoring that disrupted the quality of sleep or daily activities; and [3] who planned to undergo adenoidectomy and tonsillectomy. Excluded were those who displayed [1]: symptoms of acute infection at the time of the surgery, and received antibiotic therapy within the previous 4 weeks [2]; congenital anomalies including clef palate, Down syndrome, congenital heart disease, and craniofacial anomalies [3]; major systemic disease, such as diabetes, nephrotic disease, autoimmune disorders, immunodeficiency, malignancy, and other chronic illnesses; or [4] known allergic conditions such as asthma, allergic rhinitis, or history of allergies. As we defined that tonsils with hypertrophy score $<3$ were not hypertrophic, the patients with SDB and adenoid hypertrophy, and no tonsillar hypertrophy or inflammation were collected as controls. A total of 45 patients were included in our study, including 20 patients in control group, 10 patients in TH group, and 15 patients in $\mathrm{TH}+\mathrm{RI}$ group.

TE was conducted using plasma wand with a highfrequency electrosurgery system (Coblator II, ArthroCare Corporation, Austin, TX, USA). TE procedures were performed by surgeons with $\geq 5$ years' operating experience. The tonsils were completely removed during TE. The tissues that were not required for pathological examination were immediately collected and delivered into icy phosphate buffered saline (PBS) plus antibiotics in a $-70^{\circ} \mathrm{C}$ refrigerator within half an hour after excision under aseptic conditions.

\section{Histopathological examination}

Tonsil tissues were fixed in $4 \%$ paraformaldehyde (PFA) for $16 \mathrm{~h}$, then paraffin-embedded. The sections $(5 \mu \mathrm{m}$ thickness) were prepared and stained with Masson or hematoxylin-eosin (H\&E) and analyzed under the light microscope.

\section{Real time quantitative PCR (qRT-PCR)}

Total RNA was isolated from the tonsil using the Trizol reagent (Takara Bio Inc., Japan) following the manufacturer's 
instructions, and reverse-transcribed using reverse transcription kit (Takara Bio Inc., Japan). qRT-PCR was performed using SYBR Green master mix (Vazyme) and 7500 Real-Time PCR System (Applied Biosystems, Foster City, CA, USA). Primers used for qRT-PCR are shown in Table 1. Cycling conditions were $95^{\circ} \mathrm{C}$ for $10 \mathrm{~min}$, followed by 40 cycles of $95^{\circ} \mathrm{C}$ for $15 \mathrm{~s}$ and $60^{\circ} \mathrm{C}$ for $1 \mathrm{~min}$. The amount of mRNA for each gene was standardized with the internal control GAPDH, and calculated using the comparative cycle threshold $(\Delta \Delta \mathrm{Ct})$ method.

\section{ELISA assay}

The PGE2 levels in tonsils were determined by the ELISA kit (Elabscience, Wuhan, China) according to the manufacturer's instructions.

\section{Statistical analysis}

All the data were presented as mean \pm SEM. GraphPad Prism version 5.0 (GraphPad Software, La Jolla, CA, USA) software was used for statistical analyses, including one-way analysis of variance (ANOVA) for multiple comparisons. An unpaired Student's $t$-test was also performed to determine any significant difference between two groups. $P<0.05$ was considered statistically significant.

\section{Results}

Pathological features of tonsils in each group

$H \& E$ staining showed that the tonsils in the control group were composed of lymphoid tissues, superficial squamous epithelium, and some lymphoid nodules. The tonsils in $\mathrm{TH}$ group showed lymphoid hyperplasia, increased lymphoid follicles, and enlarged germinal centers. Besides these three changes, the tonsils in $\mathrm{TH}+\mathrm{RI}$ group showed the epithelium with papillary hyperplasia or high-level infiltration of inflammatory cells (Fig. 1a). Masson staining showed that the tonsils in $\mathrm{TH}+\mathrm{RI}$ group had developed more significant interstitial fibrosis, compared with the other two groups (Fig. 1b).

Table 1 Primers used for qRT-PCR

\begin{tabular}{|c|c|c|}
\hline Primer & Forward $\left(5^{\prime} \rightarrow 3^{\prime}\right)$ & Reverse $\left(5^{\prime} \rightarrow 3^{\prime}\right)$ \\
\hline$\overline{V P 1}$ & AGTCCTCCCACGTCACTCAC & TGATCACTAGGGTGGCATCA \\
\hline IFN-a & GCCTCGCCCTITGCTITACT & CTGTGGGTCTCAGGGAGATCA \\
\hline RIG-I & CTGGACCCTACCTACATCCTG & GGCATCCAAAAAGCCACGG \\
\hline MAVS & CAGGCCGAGCCTATCATCTG & GGGCTTTGAGCTAGTTGGCA \\
\hline NLRP3 & CGTGAGTCCCATTAAGATGGAGT & CCCGACAGTGGATATAGAACAGA \\
\hline TLR1 & TGAACCTCAAGCACTTGGACC & CCCATAAGTCTCTCCTAAGACCA \\
\hline TLR2 & ATCCTCCAATCAGGCTTCTCT & GGACAGGTCAAGGCTIITTACA \\
\hline TLR3 & TTGCCTTGTATCTACTITTGGGG & TCAACACTGTTATGTTTGTGGGT \\
\hline TLR4 & AGACCTGTCCCTGAACCCTAT & CGATGGACTTCTAAACCAGCCA \\
\hline TLR5 & TCCCTGAACTCACGAGTCTIT & GGTTGTCAAGTCCGTAAAATGC \\
\hline TLR7 & TCGTGGACTGCACAGACAAG & GGTATGTGGTTAATGGTGAGGGT \\
\hline TNF-a & ССTCTCTCTAATCAGCCCTCTG & GAGGACCTGGGAGTAGATGAG \\
\hline IL-6 & ACTCACCTCTTCAGAACGAATTG & CCATCTITGGAAGGTTCAGGTTG \\
\hline $\mathbb{I L}-1 \beta$ & ATGATGGCTTATTACAGTGGCAA & GTCGGAGATTCGTAGCTGGA \\
\hline$N F-K B$ & AACAGAGAGGATTCGTTTCCG & TTGACCTGAGGGTAAGACTTCT \\
\hline IL-7 & TTCCTCCСCTGATCCTTGTTC & CTTGCGAGCAGCACGGAATA \\
\hline $\mathrm{IL}-10$ & GACTTTAAGGGTTACCTGGGTTG & TCACATGCGCCTTGATGTCTG \\
\hline IL-12A & CCTTGCACTTCTGAAGAGATTGA & ACAGGGCCATCATAAAAGAGGT \\
\hline $\mathrm{IL}-17 \mathrm{~A}$ & AGATTACTACAACCGATCCACCT & GGGGACAGAGTTCATGTGGTA \\
\hline IL-18 & TCTTCATTGACCAAGGAAATCGG & TCCGGGGTGCATTATCTCTAC \\
\hline $\cos 2$ & GAATCATTCACCAGGCAAATT & TCTGTACTGCGGGTGGAACA \\
\hline EP1 & ACCTTCTITGGCGGCTCTC & CCAACACCAGCATTGGGCT \\
\hline EP2 & GCTCCTTGCCTTTCACGATTT & AGGATGGCAAAGACCCAAGG \\
\hline EP3 & AGCTTATGGGGATCATGTGC & TTCTGCTTCTCCGTGTGTG \\
\hline EP4 & CGCTCGTGGTGCGAGTATT & AGGGGTCTAGGATGGGGTTC \\
\hline GAPDH & CGCTCTCTGCTCCTCCTGTT & CATGGGTGGAATCATATTGG \\
\hline
\end{tabular}




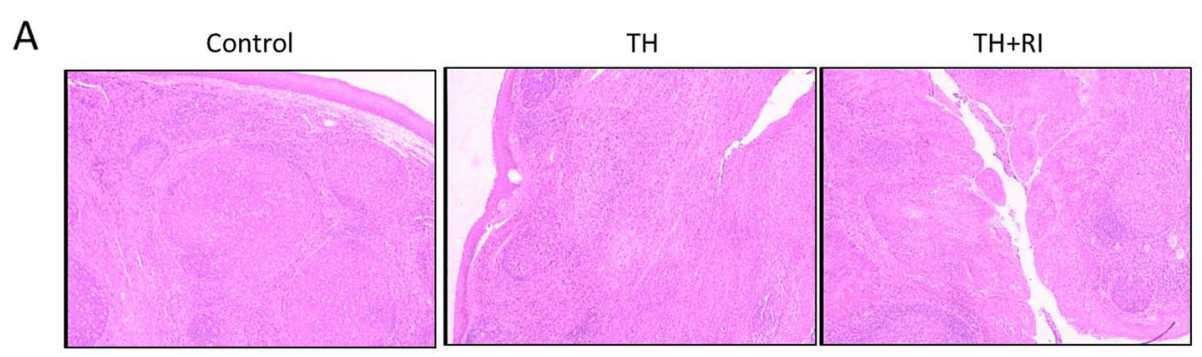

B

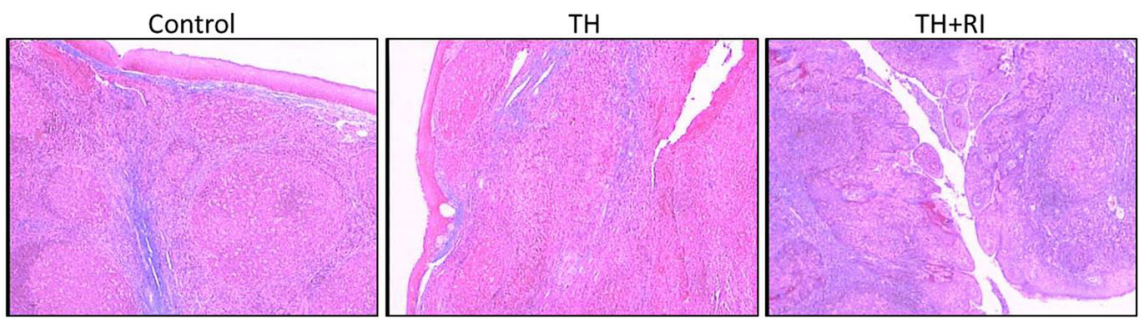

Fig. 1 Pathological features of tonsils in each group. (a) Tonsil sections were stained with H\&E and evaluated by microscope (× 200). (b) Tonsil sections were stained with Masson and evaluated by microscope $(\times 200)$

Viral infection and innate immune response in each group With qRT-PCR, we found that the expression levels of VP1 and IFN- $\alpha$ in TH group were significantly higher than that in the control group, but that in $\mathrm{TH}+\mathrm{RI}$ group was significantly lower than that in the TH group (Fig. 2a\&b). We next examined the pathways involved in innate immune response caused by the virus. We found that the mRNA levels of RIG-I and MAVS in TH group were significantly higher than that in the control group, while the mRNA levels of RIG-I and MAVS in TH + RI group were lower than that in TH group (Fig. 2c\&d). The expression profiles of RIG-I and MAVS were consistent with that of VP1 and TNF- $\alpha$. NLRP3, a component of the innate immune system, was also detected in

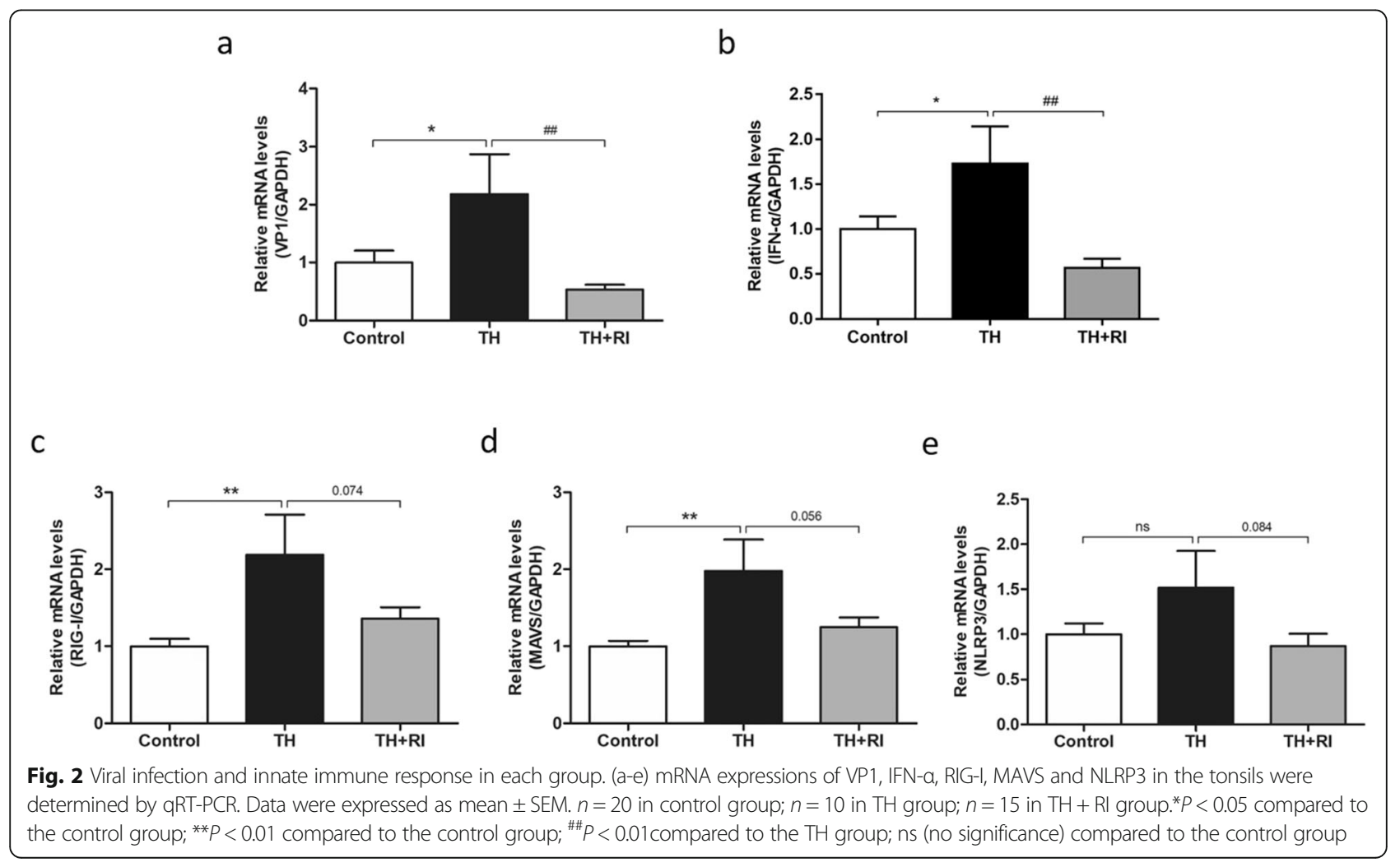


each group. The expression of NLRP3 in TH group was up-regulated, compared with the control group, while the expression level of NLRP3 in TH + RI group significantly decreased (Fig. 2e). These results indicate that the innate immune response in the tonsil was more active in $\mathrm{TH}$ group than in $\mathrm{TH}+\mathrm{RI}$ group.

\section{Expression of toll-like receptors (TLRs) in each group}

TLRs and their signaling play a crucial role in innate immune response [16]. Therefore, we examined the expression of TLRs. Compared with the control group, the expression levels of TLR1, TLR2, TLR4 and TLR7 in TH group were significantly up-regulated (Fig. 3a, b, d\&f). TLR3 and TLR5 in TH group did not change significantly (Fig. 3c\&e). The expression levels in TLRs (especially TLR4 and TLR7) in TH + RI group were significantly decreased, compared with TH group (Fig. 3d\&f). These results indicate that TLR1, TLR2, TLR4, TLR7 may be involved in the activation of the innate immune response in $\mathrm{TH}$ group.

\section{Inflammatory response in each group of tonsils}

To assess the inflammatory response, we examined the mRNA levels of TNF- $\alpha$, IL- 6, IL- $1 \beta$ and NF- $\kappa$ B. The results showed that the expression levels of these four inflammatory factors in $\mathrm{TH}$ group were significantly higher than those in the control group, while these inflammatory factors in $\mathrm{TH}+\mathrm{RI}$ group were increased to varying degrees, compared with the control group, but this increase was less obvious than that in the $\mathrm{TH}$ group. In particular, the mRNA levels of IL- $1 \beta$ and NF- $\mathrm{BB}$ were significantly lower than those in TH group (Fig. 4a-d). These results suggested that the inflammatory response in $\mathrm{TH}$ group was stronger than that in $\mathrm{TH}+\mathrm{RI}$ group. We also tested the mRNA levels of IL-7, IL-10, IL-12A, IL-17A and IL-18. The results showed that IL-7 and IL10 levels in $\mathrm{TH}$ group had an increasing trend, compared with the control group, and the levels in $\mathrm{TH}+\mathrm{RI}$ group were significantly lower than those in $\mathrm{TH}$ group (Fig. 5a\&b). The levels of IL-12A, IL-17A and IL-18 in $\mathrm{TH}$ group were not significantly different from those in the control group. IL-12A and IL-17A levels in TH + RI group were not significantly different from those in $\mathrm{TH}$ group (Fig. 5c-e).

\section{Expression of COX-2, PGE2 and its receptors in each group}

Cyclooxygenase (COX) catalyzes Cox (bis-oxygenase) reaction in which arachidonic acid is converted into PGG2 and then PGG2 is reduced by two electrons into PGH2, a precursor to all prostanoids, including PGE2, PGD2, PGF2, PGI2, and thromboxane. Prostaglandins are critical mediators in inflammation [17]. Through assessing the expression of COX-2, PGE2 and its receptors, we teased out the prostaglandin-related signaling pathways in the tonsil inflammatory response. The results of qRTPCR showed that the expression of COX-2 in TH group was significantly higher than that in the control group.

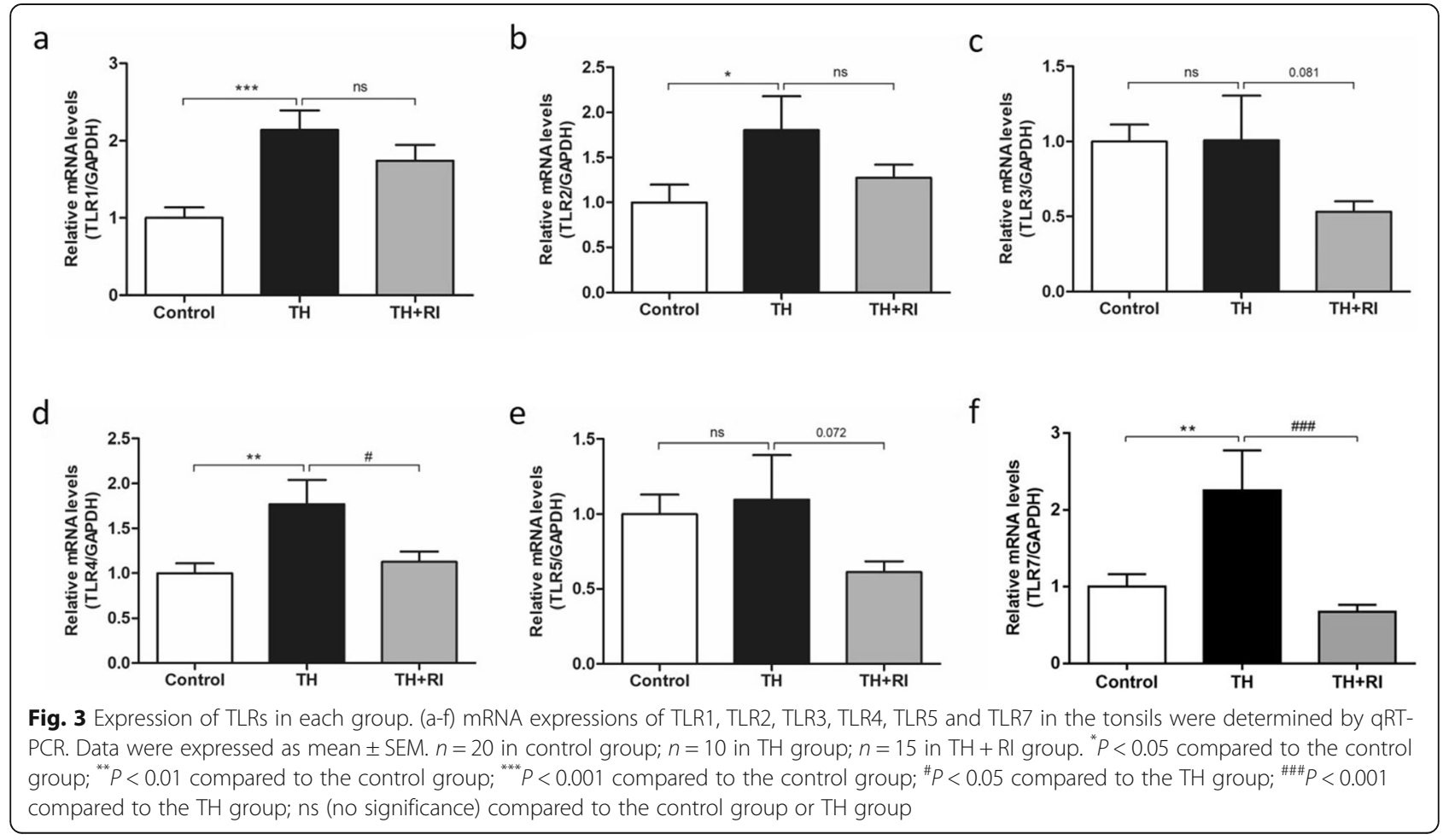


a

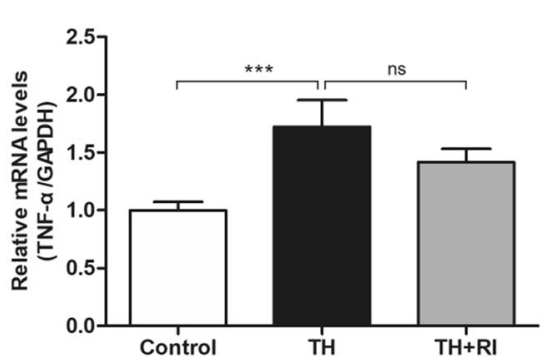

C

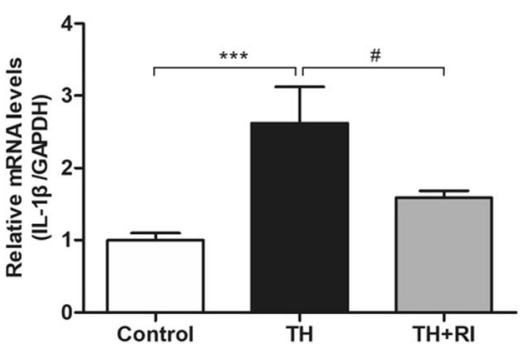

b

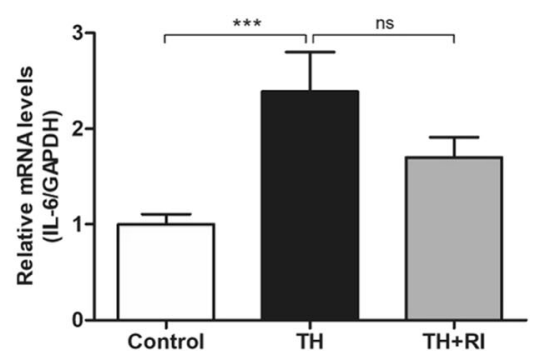

d

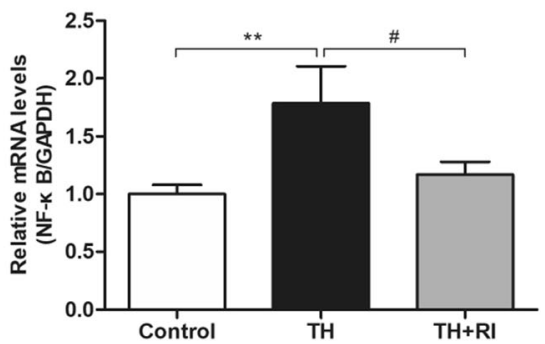

Fig. 4 Inflammatory response in each group. (a-d) mRNA expressions of TNF- $a, I L-6, I L-1 \beta$ and NF-KB in the tonsils were determined by qRT-PCR. Data were expressed as mean \pm SEM. $n=20$ in control group; $n=10$ in TH group; $n=15$ in TH + Rl group. ${ }^{* *} P<0.01$ compared to the control group; ${ }^{* * *} P<0.001$ compared to the control group; ${ }^{\# P}<0.05$ compared to the TH group; ns (no significance) compared to the $\mathrm{TH}$ group

a

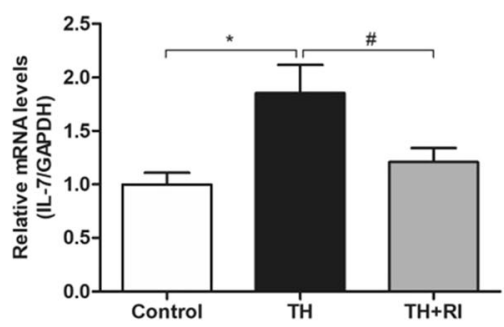

b

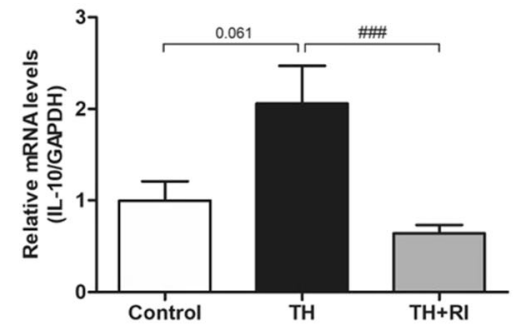

C

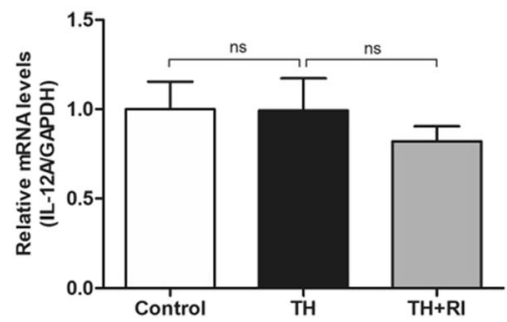

d

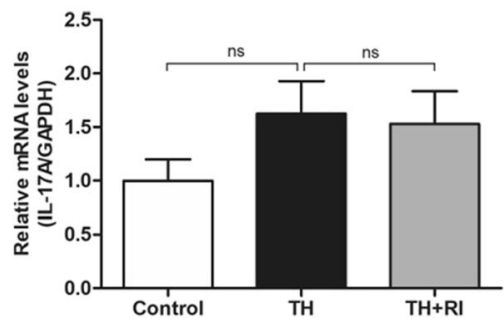

e

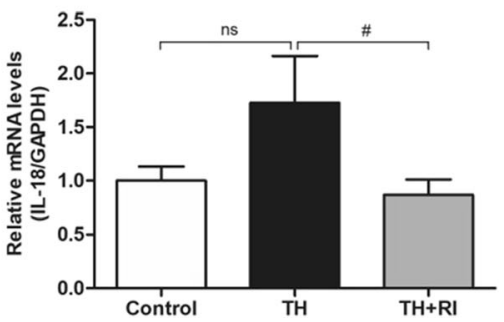

Fig. 5 Expression of some other inflammatory factors in each group. (a-e) mRNA expressions of IL-7, IL-10, IL-12A, IL-17A and IL-18 in the tonsils were determined by qRT-PCR. Data were expressed as mean \pm SEM. $n=20$ in control group; $n=10$ in TH group; $n=15$ in $T H+R l$ group. ${ }^{*} P<0.05$ compared to the control group; ${ }^{\#}<<0.05$ compared to the TH group; ${ }^{\# \#} P<0.001$ compared to the TH group; ns (no significance) compared to the control group or TH group 
The expression level of COX-2 in $\mathrm{TH}+\mathrm{RI}$ group was not significantly higher than that in the control group, but significantly lower than that in $\mathrm{TH}$ group (Fig. 6a). The ELISA results also showed that the level of PGE2 in TH group was significantly upregulated and higher than that in $\mathrm{TH}+\mathrm{RI}$ group (Fig. 6b). We then tested the receptors for PGE2, including EP1, EP2, EP3 and EP4, by qPCR. The results showed that only the expression of EP4 was significantly changed in the three groups. The expression of EP4 in TH group was significantly higher than that in the control group, while that in $\mathrm{TH}+\mathrm{RI}$ group was close to that in the control group (Fig. $6 \mathrm{c}-\mathrm{f}$ ). These results suggest that the COX-2/PGE2/EP4 axis may be involved in the tonsillar inflammatory response.

\section{Discussion}

Tonsil hypertrophy is a common otolaryngological disease, affecting $5-27 \%$ of children with primary snoring [18] and $10-12 \%$ of SDB children aged 2-8 years [6].
The etiology of hypertrophy in tonsillar lymphoid tissue remains unknown.

In the present study, the high expression of VP1 in the simple hypertrophic tonsils indicated that tonsil hypertrophy may be caused by viral infection. The innate immune system serves as the first line of defense against various microorganisms. Recent studies have shown various molecules playing critical roles in innate antiviral immune response [19-21]. The RIG-I-MAVS-mediated antiviral immune response is triggered in the host upon the invasion of pathogens. RIG-I recognizes viral RNA, undergoes conformational changes, and releases its CARDs domain. E3 ubiquitin ligase TRIM25 is recruited to catalyze the ubiquitination of K63 in RIG-I, and then binds to the downstream linker protein MAVS to transmit anti-transfer virus signal [22]. NLRP3 is an innate immune signaling receptor. Once activated, it initiates caspase1-mediated proteolytic activation of the IL-1 $\beta$ family of cytokines, and induces an inflammatory response [23-25]. The expression of these innate immune a

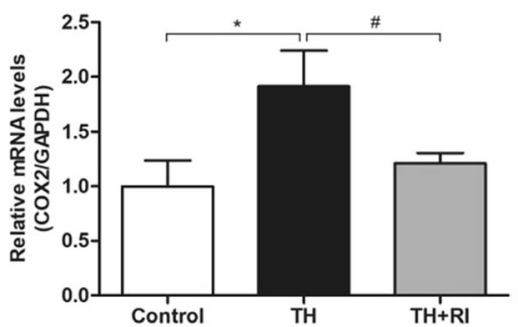

C

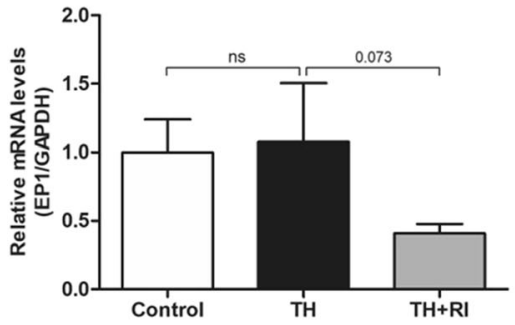

e

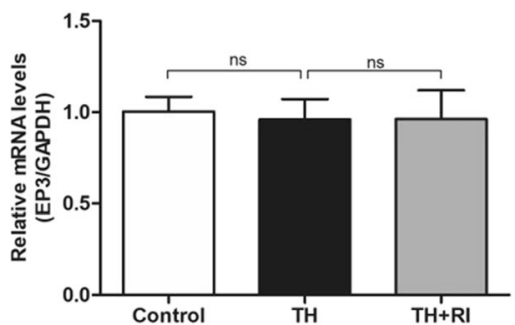

b

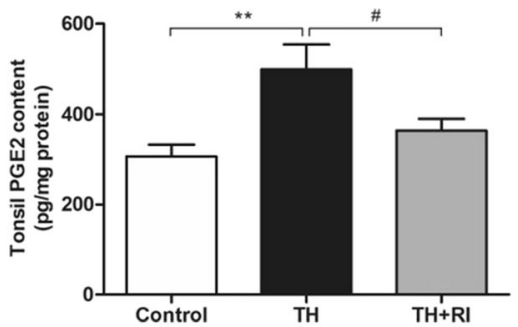

d

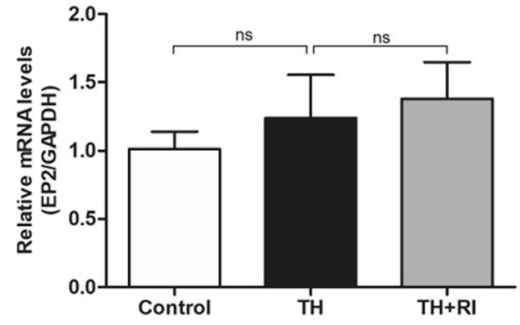

f

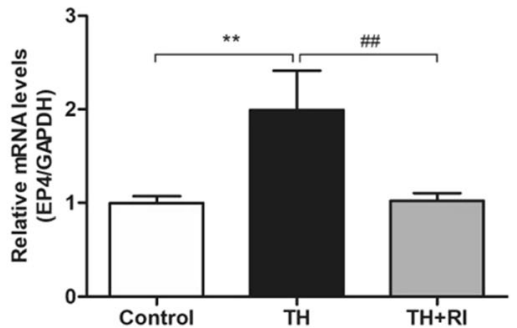

Fig. 6 The changes of COX-2, PGE2 and its receptors in each group. (a) mRNA expression of COX-2 in the tonsil was determined by qRT-PCR. (b) PGE2 content in the tonsil was determined by ELISA. (c-f) mRNA expression of EP1, EP2, EP3 and EP4 in the tonsil was determined by qRT-PCR. Data were expressed as mean \pm SEM. $n=20$ in control group; $n=10$ in TH group; $n=15$ in TH + RI group. ${ }^{*} P<0.05$ compared to the control group; ${ }^{* *} P<0.01$ compared to the control group; ${ }^{\#} P<0.05$ compared to the TH group; ${ }^{\# \#} P<0.01$ compared to the TH group; ns (no significance) compared to the control group or TH group 
factors, including RIG-I, MAVS and NLRP3, may be upregulated by viral infections in simple hypertrophic tonsils.

The innate immune system relies on TLRs to recognize and bind pathogen-associated molecules. It has been demonstrated that TLRs recognize viruses and initiate a series of cellular antiviral responses via intracellular signaling pathways [26, 27]. Our results showed that TLR4 and TLR7 were involved in virus-geared innate immune response in simple hypertrophic tonsils. The activation of TLR initiates downstream signaling cascades (like MAPK or NF- $\mathrm{kB}$ ) and consequent proinflammatory response [28, 29]. TLR7 can activate NF- $\mathrm{kB}$ to mediate the immune inflammatory response. Consistent with their performance in innate immune response, IFN- $\alpha, \mathrm{NF}-\mathrm{kB}, \mathrm{TNF}-\alpha, \mathrm{IL}-1 \beta$ and IL-7 showed up-regulated expression in the simple hypertrophic tonsils. The high levels of TNF- $\alpha$ and IL- 6 in TH group reflected that monocyte-macrophage transformation was enhanced, thus inducing the activation and proliferation of endothelial cells and fibroblasts. In this process, immunologically active tissue can be gradually replaced by fibrotic tissue [30]. This may be the reason why TH group exhibited stronger inflammation than $\mathrm{TH}+\mathrm{RI}$ group.

Over activation of TLR4 signaling pathway can cause over expression of various inflammatory mediators, including COX-2 [31]. Recent studies have verified the contribution of inducible COX-2 and its downstream prostaglandin signaling pathways in modulating inflammatory responses [32-34]. PGE2 is generated through a sequential enzyme cascade of COX/PGE2 synthases (PGES) [35], and mediated via four different G-protein-coupled PGE receptors (e.g. EP1, EP2, EP3, and EP4) [36]. PGE2 appears to facilitate the function of helper $\mathrm{T}$ cells mainly via EP4 in vivo, and modulate the pathogenesis of various chronic inflammation and autoimmune diseases [37]. In the simple hypertrophic tonsils, the up-regulation of COX2, PGE2 and EP4 indicates that this pathway may be responsible for the inflammatory response and formation of fibroblasts. Whether this pathway can be used as a target in the treatment of tonsil hypertrophy requires further research.

Also, RI may lead to fibrosis of the tonsils and to fixation of the tonsil in its bed. The volume of the tonsils cannot be relied on to establish the diagnosis of tonsillitis, but to define its symptoms, such as SDB [38]. Different production of inflammatory and innate immune mediators suggested that tonsillar tissue hypertrophy may be regulated by divergent mechanisms and have different immunophenotype. Detecting these differences may help otolaryngologists to administer target treatments for hypertrophic tonsils. However, lacking data of RI is a limitation of our study, which should be resolved in our future work.
In summary, our results suggest that innate immune and inflammatory responses are more active in simple hypertrophic tonsils, rather than hypertrophic tonsils with recurrent inflammation. On the other hand, a local relative immune deficiency in the hypertrophic tonsils may be a causative factor for recurrent tonsillitis in $\mathrm{TH}+$ RI. These differences, together with the patient's clinical manifestations, suggest that tonsillar hypertrophy might be regulated by diverse immune and/or inflammatory mechanism. Our findings provided a new understanding on the pathogenesis of tonsil hypertrophy, through which novel therapeutic strategies might be created.

\section{Acknowledgements \\ We thank associate professor Yong-Ke Cao at the College of Foreign Lan- guages of Nanjing Medical University for professional English-language proofreading of the manuscript. We also thank Chun-Li Wang, MSC and Jiao- Jiao Xing, MSc at the Nanjing Key Laboratory of Pediatrics, Children's Hospital of Nanjing Medical University for delivering and preserving samples.}

\section{Authors' contributions}

Q.H., H.H. and W.L. performed the experimental study and data collection. H.H. analyzed and interpreted the data. Q.H. and H.H. were major contributors in writing the manuscript. Q.H. X.C. and L.C. revised the manuscript and gave the material support. Q.H. and L.C. conceived and supervised the whole project. All authors read and approved the final manuscript.

\section{Funding}

This work was supported by grants from Nanjing General Project of Medical Science and Technology Development (YKK16175), People's Republic of China.

\section{Availability of data and materials}

The datasets used and/or analyzed during the current study are available from the corresponding author on reasonable request.

\section{Ethics approval and consent to participate}

This study was approved by the ethics committee of Children's Hospital of Nanjing Medical University (Approval number: 2016010003-1.1). Informed consent was obtained from the legal caregiver of each participant.

Consent for publication

Not applicable.

\section{Competing interests}

The authors declare that they have no competing interests.

\section{Author details}

${ }^{1}$ Department of Otorhinolaryngology, Children's Hospital of Nanjing Medical University, Nanjing, China. ${ }^{2}$ Nanjing Key Laboratory of Pediatrics, Children's Hospital of Nanjing Medical University, Nanjing, China. ${ }^{3}$ Department of Otorhinolaryngology, The First Affiliated Hospital, Nanjing Medical University, 300 Guangzhou Road, Nanjing 210029, Jiangsu, China.

Received: 12 January 2020 Accepted: 18 May 2020

Published online: 01 June 2020

\section{References}

1. El Hennawi DED, Geneid A, Zaher S, Ahmed MR. Management of recurrent tonsillitis in children. Am J Otolaryngol. 2017;38:371-4.

2. Kamekura R, Imai R, Takano $\mathrm{K}$, et al. Expression and localization of human defensins in palatine tonsils. Adv Otorhinolaryngol. 2016;77:112-8.

3. Friedman NR, Prager JD, Ruiz AG, Kezirian EJ. A pediatric grading scale for lingual tonsil hypertrophy. Otolaryngol Head Neck Surg. 2016;154:171-4.

4. Prosser JD, Shott SR, Rodriguez O, Simakajornboon N, Meinzen-Derr J, Ishman SL. Polysomnographic outcomes following lingual tonsillectomy for 
persistent obstructive sleep apnea in Down syndrome. Laryngoscope. 2017; 127:520-4.

5. May JG, Shah P, Lemonnier L, Bhatti G, Koscica J, Coticchia JM. Systematic review of endoscopic airway findings in children with gastroesophageal reflux disease. Ann Otol Rhinol Laryngol. 2011;120:116-22.

6. Benninger M, Walner D. Obstructive sleep-disordered breathing in children. Clin Cornerstone. 2007;9(Suppl 1):S6-12.

7. Silva J, Almeida ECS, Sousa JC, Reis LGV, Sousa JB, Etchebehere RM. Tonsillar hyperplasia and recurrent acute tonsillitis in children: Immunohistochemical evaluation of the lymphatic tissue. Int J Pediatr Otorhinolaryngol. 2019;121: $15-9$.

8. Paradise JL, Bluestone CD, Colborn DK, Bernard BS, Rockette HE, Kurs-Lasky $\mathrm{M}$. Tonsillectomy and adenotonsillectomy for recurrent throat infection in moderately affected children. Pediatrics. 2002;110:7-15.

9. Gao Y, Mi J, Chen F, et al. Detection of GSK-3beta activation index in pediatric chronic tonsillitis is an indicator for chronic recurrent inflammation. Am J Otolaryngol. 2018;39:277-81.

10. Randel A. AAO-HNS guidelines for tonsillectomy in children and adolescents. Am Fam Physician. 2011;84:566-73.

11. Isaiah A, Hamdan H, Johnson RF, Naqvi K, Mitchell RB. Very severe obstructive sleep apnea in children: outcomes of Adenotonsillectomy and risk factors for persistence. Otolaryngol Head Neck Surg. 2017;157:128-34.

12. Zonato Al, Bittencourt $L R$, Martinho FL, Junior JF, Gregorio LC, Tufik S. Association of systematic head and neck physical examination with severity of obstructive sleep apnea-hypopnea syndrome. Laryngoscope. 2003;113: 973-80.

13. Friedman M, Tanyeri $\mathrm{H}$, La Rosa M, et al. Clinical predictors of obstructive sleep apnea. Laryngoscope. 1999;109:1901-7.

14. Zonato Al, Martinho FL, Bittencourt LR, de Oliveira Campones Brasil O, Gregorio LC, Tufik S. Head and neck physical examination: comparison between nonapneic and obstructive sleep apnea patients. Laryngoscope. 2005;115:1030-4

15. Bicknell PG. Role of adenotonsillectomy in the management of pediatric ear, nose and throat infections. Pediatr Infect Dis J. 1994;13:S75-8; discussion S78-9.

16. Takeda K, Akira S. Toll-like receptors in innate immunity. Int Immunol. 2005; 17:1-14.

17. Dilek FH, Sahin O, Tokyol C, Mazlum M, Aycicek A. Expression of cyclooxygenase-1 and 2 in chronic tonsillitis. Indian J Pathol Microbiol. 2010; 53:451-4.

18. Brown KA. Outcome, risk, and error and the child with obstructive sleep apnea. Paediatr Anaesth. 2011:21:771-80.

19. Xiang Y, Tang JJ, Tao W, Cao X, Song BL, Zhong J. Identification of cholesterol 25-hydroxylase as a novel host restriction factor and a part of the primary innate immune responses against hepatitis $C$ virus infection. J Virol. 2015;89:6805-16.

20. West AP, Khoury-Hanold W, Staron M, et al. Mitochondrial DNA stress primes the antiviral innate immune response. Nature. 2015:520:553-7.

21. Moskwa S, Piotrowski W, Marczak J, et al. Innate immune response to viral infections in primary bronchial epithelial cells is modified by the atopic status of asthmatic patients. Allergy Asthma Immunol Res. 2018;10:144-54.

22. Hao Q, Jiao S, Shi Z, et al. A non-canonical role of the $\mathrm{p} 97$ complex in RIG-I antiviral signaling. EMBO J. 2015;34:2903-20.

23. Mangan MSJ, Olhava EJ, Roush WR, Seidel HM, Glick GD, Latz E. Targeting the NLRP3 inflammasome in inflammatory diseases. Nat Rev Drug Discov. 2018;17:588-606.

24. Kim BG, Lee PH, Lee SH, Park MK, Jang AS. Effect of TiO (2) nanoparticles on Inflammasome-mediated airway inflammation and responsiveness. Allergy Asthma Immunol Res. 2017;9:257-64.

25. Halfmann P, Hill-Batorski L, Kawaoka Y. The induction of IL-1 beta secretion through the NLRP3 Inflammasome during Ebola virus infection. J Infect Dis. 2018;218:5504-7.

26. Kurt-Jones EA, Popova $L$, Kwinn $L$, et al. Pattern recognition receptors TLR4 and CD14 mediate response to respiratory syncytial virus. Nat Immunol. 2000;1:398-401.

27. Bowie A, Kiss-Toth E, Symons JA, Smith GL, Dower SK, O'Neill LA. A46R and A52R from vaccinia virus are antagonists of host IL-1 and toll-like receptor signaling. Proc Natl Acad Sci U S A. 2000;97:10162-7.

28. Kawai T, Akira S. Toll-like receptors and their crosstalk with other innate receptors in infection and immunity. Immunity. 2011;34:637-50.
29. Medvedev AE, Lentschat A, Wahl LM, Golenbock DT, Vogel SN. Dysregulation of LPS-induced toll-like receptor 4-MyD88 complex formation and IL-1 receptor-associated kinase 1 activation in endotoxin-tolerant cells. J Immunol. 2002;169:5209-16.

30. Serpero LD, Kheirandish-Gozal L, Dayyat E, Goldman JL, Kim J, Gozal D. A mixed cell culture model for assessment of proliferation in tonsillar tissues from children with obstructive sleep apnea or recurrent tonsillitis. Laryngoscope. 2009;119:1005-10.

31. Fukata M, Chen A, Klepper A, et al. Cox-2 is regulated by toll-like receptor-4 (TLR4) signaling: role in proliferation and apoptosis in the intestine. Gastroenterology. 2006;131:862-77.

32. Pradhan SS, Salinas K, Garduno AC, et al. Anti-inflammatory and neuroprotective effects of PGE2 EP4 signaling in models of Parkinson's disease. J Neuroimmune Pharmacol. 2017;12:292-304.

33. Shi J, Johansson J, Woodling NS, Wang Q, Montine TJ, Andreasson K. The prostaglandin E2 E-prostanoid 4 receptor exerts anti-inflammatory effects in brain innate immunity. J Immunol. 2010;184:7207-18.

34. Woodling NS, Wang Q, Priyam PG, et al. Suppression of Alzheimerassociated inflammation by microglial prostaglandin-E2 EP4 receptor signaling. J Neurosci. 2014;34:5882-94.

35. Murakami M, Naraba H, Tanioka T, et al. Regulation of prostaglandin E2 biosynthesis by inducible membrane-associated prostaglandin E2 synthase that acts in concert with cyclooxygenase-2. J Biol Chem. 2000;275:32783-92.

36. Cho JS, Han IH, Lee HR, Lee HM. Prostaglandin E2 induces IL-6 and IL-8 production by the EP receptors/Akt/NF-kappaB pathways in nasal polypderived fibroblasts. Allergy Asthma Immunol Res. 2014:6:449-57.

37. Kawahara K, Hohjoh H, Inazumi T, Tsuchiya S, Sugimoto Y. Prostaglandin E2induced inflammation: relevance of prostaglandin E receptors. Biochim Biophys Acta. 2015;1851:414-21.

38. Windfuhr JP, Toepfner N, Steffen G, Waldfahrer F, Berner R. Clinical practice guideline: tonsillitis I. diagnostics and nonsurgical management. Eur Arch Otorhinolaryngol. 2016;273:973-87.

\section{Publisher's Note}

Springer Nature remains neutral with regard to jurisdictional claims in published maps and institutional affiliations.

Ready to submit your research? Choose BMC and benefit from:

- fast, convenient online submission

- thorough peer review by experienced researchers in your field

- rapid publication on acceptance

- support for research data, including large and complex data types

- gold Open Access which fosters wider collaboration and increased citations

- maximum visibility for your research: over $100 \mathrm{M}$ website views per year

At BMC, research is always in progress.

Learn more biomedcentral.com/submissions 